\title{
Peripheral arterial disease and its correlates in patients with type 2 diabetes mellitus in a teaching hospital in northern Nigeria: a cross-sectional study
}

\author{
Orighomisan Freda Agboghoroma ${ }^{1,2^{*}}$, Fatai Momodu Akemokwe ${ }^{2}$ and Fabian H. Puepet ${ }^{1}$
}

\begin{abstract}
Background: Peripheral arterial disease (PAD) is a risk factor for diabetic foot ulcer, limb amputation as well as coronary heart disease. It is more common in patients with diabetes mellitus (DM) and co-exists with peripheral neuropathy. Prevalence of PAD in type 2 DM patients in northern Nigeria is largely unknown. We investigated the occurrence and factors associated with PAD among patients with type $2 \mathrm{DM}$ in a tertiary hospital in northern Nigeria.

Methods: This was a cross- sectional analytic study. We recruited 200 patients with type 2 DM consecutively from the diabetes clinic of the Jos University Teaching Hospital. Ankle brachial index was assessed for each participant. Clinical information, anthropometric indices and blood samples were collected for assay. Data was analysed using CDC Epi-Info and logistic regression analysis was used to determine independent correlates of PAD.

RESULTS:PAD was present in $38.5 \%(n=77)$ of subjects and it was associated with the female sex, age $\geq 50$ years, Body mass index (BMI) $\geq 25 \mathrm{~kg} / \mathrm{m}^{2}$ and low HDL cholesterol levels. However, on multiple logistic regression, a $\mathrm{BMI} \geq 25 \mathrm{~kg} / \mathrm{m}^{2}$ and a low $\mathrm{HDL}$ cholesterol level were independent correlates of $\mathrm{PAD}$ (adjusted $\mathrm{OR}=2.13,95 \% \mathrm{Cl}=$ $1.04-4.36$ and adjusted $\mathrm{OR}=2.31,95 \% \mathrm{Cl}=1.04-5.15$, respectively).
\end{abstract}

Conclusion: PAD is present in more than a third of patients with type $2 \mathrm{DM}$ in a tertiary hospital in northern Nigeria. A BMl of $\geq 25 \mathrm{~kg} / \mathrm{m}^{2}$ and low HDL cholesterol levels were independent correlates of PAD.

Keywords: Peripheral arterial disease, Diabetes mellitus, Type 2, Correlates, Nigeria

\section{Background}

Peripheral arterial disease (PAD) is a chronic complication of diabetes mellitus (DM) and a risk factor for foot ulceration and amputation- more than two-thirds of patients with diabetic foot ulceration have associated PAD [1]. This arthero - occlusive disease of the extremities does increase the risk of coronary artery disease as well

\footnotetext{
* Correspondence: misan.aroma@gmail.com

'Jos University Teaching Hospital, Jos, Plateau State, Nigeria

${ }^{2}$ Present address: Medical Research Council at the London School of Hygiene and Tropical Medicine, Fajara, Gambia
}

[2, 3]. Although PAD occurs in non- diabetic patients, it is up to four times more common in patients with DM [4]. Symptoms such as intermittent claudication and calf pain at rest suggest PAD but in DM, these symptoms may be obscured by the concomitant presence of peripheral neuropathy [5].

The prevalence of PAD differs depending on the modality used [6]. Studies have used the presence of symptoms, the absence of peripheral pulses in the extremities and more recently, ankle brachial index (ABI) to assess $\mathrm{PAD}$. In patients with $\mathrm{DM}$, the presence of $\mathrm{PAD}$ as

C C The Author(s). 2020 Open Access This article is licensed under a Creative Commons Attribution 4.0 International License, which permits use, sharing, adaptation, distribution and reproduction in any medium or format, as long as you give appropriate credit to the original author(s) and the source, provide a link to the Creative Commons licence, and indicate if changes were made. The images or other third party material in this article are included in the article's Creative Commons licence, unless indicated otherwise in a credit line to the material. If material is not included in the article's Creative Commons licence and your intended use is not permitted by statutory regulation or exceeds the permitted use, you will need to obtain permission directly from the copyright holder. To view a copy of this licence, visit http://creativecommons.org/licenses/by/4.0/ The Creative Commons Public Domain Dedication waiver (http://creativecommons.org/publicdomain/zero/1.0/) applies to the data made available in this article, unless otherwise stated in a credit line to the data. 
determined by $\mathrm{ABI}$ varies from 9 to $20 \%[3,7,8]$ in Western countries and from 3.2-24.1\% [9-12] in Asia. In sub- Saharan Africa, recent studies on PAD in patients with DM estimate the occurrence of PAD to be between 28 and 52.5\% using ABI [13-15]. Ankle brachial pressure index, a ratio of the systolic blood pressure in the ankle to the systolic pressure in the arm, has 95\% specificity and $100 \%$ sensitivity for PAD at a value of $\leq 0.90[16,17]$. The American Diabetes Association recommends screening for PAD in DM patients with $\mathrm{ABI}$ and treatment to prevent further morbidity [2].

In general, the risk factors for PAD include DM, hypertension, smoking, age, obesity and dyslipidaemia [18]. However, in patients with DM there are other factors associated with PAD: hyperglycaemia and a longer duration of diabetes $[2,19]$. The major difference in the pathogenesis of atherosclerosis in DM lies in the effects of chronic hyperglycaemia. Prolonged hyperglycaemia results in augmentation of platelet activity and alterations in the vascular endothelium and coagulating factors, which favours atherosclerosis and thrombosis [1921]. Hence, searching for risk factors related to PAD and modifying them where possible may prove helpful in the prevention and management of this condition.

Few studies from sub-Saharan Africa fully examine PAD [13, 14, 22]. An in-depth knowledge of PAD in African patients with DM is necessary. Therefore, our study focuses on determining the prevalence of PAD in patients with type $2 \mathrm{DM}$ with emphasis on the clinical and biochemical factors associated with it.

\section{Methods}

This is a cross- sectional analytic study carried out at the Diabetes Clinic of the Jos University Teaching Hospital. The hospital is located in the north central Nigeria and is the main tertiary institution in the region providing referral services to seven neighbouring states with a bed capacity of 520 . We obtained ethical approval for the study from the institution's Health Research Ethical Committee (JUTH/DCS/ADM/127/XIX/5955). Participants were recruited consecutively, from March to September in 2014, after providing an informed consent. We included those who were: [1] diagnosed with DM and on anti-diabetic therapy, [2] 30 years and older at the time of diagnosis (type $2 \mathrm{DM}$ was more likely in this age group) and, [3] not on steroids or oral contraceptives. The minimum sample size was calculated using a PAD prevalence of 52.5\% [23] among patients with DM and a precision of 0.1 . However, 200 patients were enrolled to increase the statistical power of the study tests. A proforma was used to collect all the data required for the study including biodata, medications, anthropometric measurements and biochemical characteristics.
The weight and height for each patient were measured using a weighing scale and a stadiometer (Seca $\odot$ 224, United Kingdom). Weight was recorded in kilogrammes (to the nearest $0.1 \mathrm{~kg}$ ) and height in metres (to the nearest $0.01 \mathrm{~m}$ ). The Body Mass Index (BMI) was calculated as the weight of a participant divided by the square of his/her height. Waist circumference was measured using a non- stretch measuring tape and at a position midway between the costal margin and the iliac crest. An abnormal waist circumference was defined as $\geq 94 \mathrm{~cm}$ for men and $\geq 80 \mathrm{~cm}$ for women [24]. Glycosylated haemoglobin $(\mathrm{HbA} 1 \mathrm{c})$ was measured using the a latex agglutination method in the DCA 2000 analyser (Siemens, Germany) and the lipid levels were estimated using a blood chemistry autoanalyser (Hitachi 902, Mannheim, Germany).

Ankle and brachial pressures were measured using a mercury manometer (Accosons, England) and a $8-\mathrm{MHz}$ handheld vascular doppler device (LifeDop L150R, Colorado,United States). The highest systolic pressures for each limb were used to calculate the ABI with the ankle systolic pressure as the numerator and the brachial systolic pressure as the denominator. An ABI of $\leq 0.90$ in any limb was recorded as PAD. PAD was further classified into mild, moderate and severe using the ABI, as follows: mild $-0.70-0.90$; moderate $-0.40-0.69$ and severe- less than $0.40[17,25]$.

Hypertension was present if a participant was on antihypertensives or had a blood pressure of $\geq 140 / 90 \mathrm{mmHg}$ [26]. Poor glycaemic control was defined as $\mathrm{HbA1c} \geq 7 \%$ [27]. Dyslipidaemia was described as follows: elevated total cholesterol - total cholesterol value $\geq 5.2 \mathrm{mmol} / \mathrm{L}$ or Elevated Triglyceride- triglyceride level $\geq 1.7 \mathrm{mmol} / \mathrm{L}$ or Elevated low density lipoprotein(LDL) Cholesterol -LDL cholesterol $\geq 2.6 \mathrm{mmol} / \mathrm{L}$ [28]. Low High Density cholesterol was defined as values $<1.1 \mathrm{mmol} / \mathrm{L}$ for men and $<1.3 \mathrm{mmol} / \mathrm{L}$ for women [28].

Data was entered and analysed using the CDC Epiinfo software package. Comparisons between continuous variables was done using $\mathrm{t}$ - test and categorical variables using chi-square. Bivariate analysis was used to determine the relationship between PAD and other variables. Multiple logistic regression was used to determine the independent correlates of PAD- the independent variables were those which showed statistically significant associations with PAD on bivariate analysis in this study. A $p$-value of less than 0.05 was considered statistically significant.

\section{Results}

The age of participants ranged between 31 and 90 years. The prevalence of PAD was $38.5 \%(n=77)$. Mild and moderate PAD was seen in $49(24.5 \%)$ and $23(11.5 \%)$, respectively while one participant had severe PAD. Twenty 
(10\%) patients had poorly compressible arteries with ankle - brachial index of $>1.3$.

There were $83(41.5 \%)$ female participants in the study. Most of the participants were middle aged and about two- thirds had systemic hypertension in addition to DM (Table 1). Nine (4.5\%) participants had previously smoked tobacco but none was currently smoking. The anthropometric measurements are shown in Table 1: the women had a higher BMI than the men and this reached statistical significance. The males and females also differed in their cholesterol levels: the females had significantly higher total cholesterol and LDL cholesterol levels.

On bivariate analysis for the correlates of PAD, more females had PAD than males and this was statistically significant (Table 2). Persons who were 50 years and older were less likely to have PAD $(p<0.05)$. Among those with PAD, a large proportion had hypertension, abnormal waist circumference and poor glycaemic control -49 (63.6\%), 53(68.8\%) and 61(79.2\%), respectively but these did not attain statistical significance. A BMI of $\geq 25 \mathrm{~kg} / \mathrm{m} 2$ and a low HDL cholesterol was associated with the presence of PAD in this study on bivariate analysis. There was an independent association between BMI of $25 \mathrm{~kg} / \mathrm{m}^{2}$ or more, low HDL cholesterol levels and PAD on multiple logistic regression with age and sex as co-variates (Table 3). The regression model predicted $11 \%$ of the variance in PAD and correctly classified $68 \%$ of cases.

\section{Discussion}

Peripheral arterial disease was common in patients with type $2 \mathrm{DM}$ in this study: $38.5 \%$ of our DM patients had PAD. Our findings are comparable to studies in Southern Nigeria where similar populations were assessed for PAD [13, 15]. One reason for the high prevalence of PAD in our study is that DM co- exists with other risk factors for cardiovascular disease. We observed that more than two-thirds of the patients in this study had hypertension, dyslipidaemia, and were overweight or obese. Secondly, it is likely that patients with DM who present at the teaching hospital already have chronic complications of DM hence their referral. Earlier studies from sub Saharan Africa had shown a lower prevalence mainly on account of the use of symptoms and signs as proxies for estimating PAD [6]. Our results differ from studies done in Asia, US and Europe, in that the recorded prevalence in those studies were considerably lower- as low as $3.2 \%$ in a similar population in Korea [9]. A high proportion of other risk factors for PAD, such as hypertension, in Black Africans may explain the differences in the prevalence PAD in this case. Perhaps the combination of all the risk factors present in our patients resulted in our observation. Ten percent of our patients had poorly compressible arteries $(\mathrm{ABI}>1.3)$. Adding this number to the prevalence of PAD increases the prevalence to $48.5 \%$.

More females than males had PAD in this study. This was likely due to significantly increased BMI and total

Table 1 Clinical and biochemical characteristics of study participants in mean (SD) or $n$ (\%)

\begin{tabular}{|c|c|c|c|c|}
\hline Characteristic & Female $(n=83)$ & Male $(n=117)$ & $p$ value & All participants $(n=200)$ \\
\hline Age (years) & $56.5(12.5)$ & $57.4(11.3)$ & 0.65 & $56.9(11.8)$ \\
\hline Duration of DM (years) & $9.2(6.9)$ & $8.3(6.8)$ & 0.39 & $8.7(6.8)$ \\
\hline Presence of Hypertension & $61(73.5)$ & $79(67.5)$ & 0.36 & $140(70.0)$ \\
\hline Previous Tobacco Smoking* & $0(0.0)$ & $9(7.7)$ & 0.01 & $9(4.5)$ \\
\hline Previous MI or stroke & $4(4.8)$ & $8(6.8)$ & 0.55 & $12(6.0)$ \\
\hline \multicolumn{5}{|l|}{ Medications } \\
\hline Antihypertensives & $60(72.3)$ & $74(63.2)$ & 0.18 & $134(67.0)$ \\
\hline Lipid lowering drugs & $11(13.3)$ & $14(12.0)$ & 0.79 & $21(12.5)$ \\
\hline Antiplatelets & $15(18.1)$ & $22(18.8)$ & 0.90 & $37(18.5)$ \\
\hline BMI $\left(\mathrm{Kg} / \mathrm{m}^{2}\right)^{*}$ & $29.3(5.4)$ & $27.0(5.1)$ & $<0.01$ & $27.9(5.4)$ \\
\hline Waist circumference $(\mathrm{cm})$ & $97.6(9.9)$ & $94.6(12.2)$ & 0.05 & $95.8(11.4)$ \\
\hline $\mathrm{HbA1c}(\%)$ & $10.3(3.1)$ & $9.9(3.1)$ & 0.32 & $10.1(3.1)$ \\
\hline Total cholesterol $(\mathrm{mmol} / \mathrm{L})^{*}$ & $4.5(0.9)$ & $4.1(1.0)$ & 0.01 & $4.20(1.0)$ \\
\hline LDL cholesterol (mmol/L) & $2.7(0.9)$ & $2.5(0.9)$ & 0.14 & $2.6(0.5)$ \\
\hline HDLcholesterol $(\mathrm{mmol} / \mathrm{L})^{*}$ & $1.0(0.4)$ & $0.9(0.4)$ & $<0.01$ & $0.95(0.4)$ \\
\hline Triglycerides (mmol/L) & $1.5(0.7)$ & $1.6(1.1)$ & 0.65 & $1.5(0.9)$ \\
\hline$P A D^{*}$ & $39(47.0)$ & $38(32.5)$ & 0.04 & 77 (38.5) \\
\hline
\end{tabular}

${ }^{*} p<0.05$. DM Diabetes mellitus, MI Myocardial infarction, HbA1c glycosylated haemoglobin, BMI Body mass index, LDL Low density lipoprotein, HDL High density lipoprotein, PAD Peripheral arterial disease 
Table 2 Comparison of clinical and biochemical characteristics of participants with PAD

\begin{tabular}{|c|c|c|c|c|}
\hline Characteristic & PAD Absent n (\%) & PAD present $n(\%)$ & Odds ratio & 95\% Confidence interval \\
\hline Age $\geq 50$ years $^{*}$ & $97(78.9)$ & $50(64.9)$ & 0.50 & $0.26-0.94$ \\
\hline Female sex ${ }^{*}$ & $44(35.8)$ & $39(50.6)$ & 1.84 & $1.04-3.29$ \\
\hline Duration of $\mathrm{DM}>5$ years & $74(60.2)$ & $38(49.4)$ & 1.55 & $0.87-2.75$ \\
\hline Presence of hypertension & $91(74.0)$ & 49 (63.6) & 0.62 & $0.33-1.14$ \\
\hline Previous MI or Stroke & $7(5.7)$ & $5(6.5)$ & 1.15 & $0.35-3.76$ \\
\hline Previous tobacco smoking & $5(4.1)$ & $4(5.2)$ & 0.77 & $0.20-2.97$ \\
\hline \multicolumn{5}{|l|}{ Medications } \\
\hline Antihypertensives & $87(70.7)$ & $47(60.1)$ & 0.65 & $0.36-1.18$ \\
\hline Lipid lowering drugs & $16(13.0)$ & $9(11.7)$ & 0.89 & $0.37-2.12$ \\
\hline Antiplatelets & $28(22.8)$ & $9(11.7)$ & 0.47 & $0.20-1.06$ \\
\hline $\mathrm{BMI} \geq 25 \mathrm{~kg} / \mathrm{m}^{2^{*}}$ & $77(62.6)$ & $63(81.8)$ & 2.69 & $1.35-5.33$ \\
\hline Abnormal Waist Circumference & $82(66.7)$ & $53(68.8)$ & 1.10 & $0.60-2.03$ \\
\hline Poor glycaemic control & $101(82.1)$ & $61(79.2)$ & 0.83 & $0.40-1.70$ \\
\hline Elevated total cholesterol & $20(16.3)$ & $13(16.9)$ & 1.05 & $0.49-2.25$ \\
\hline Elevated LDL cholesterol & $56(45.5)$ & $43(55.8)$ & 1.50 & $0.85-2.60$ \\
\hline Low HDL cholesterol ${ }^{*}$ & $89(72.4)$ & $64(85.3)$ & 2.22 & $1.05-4.72$ \\
\hline Elevated Triglycerides & $32(26.0)$ & $21(27.3)$ & 1.07 & $0.56-2.03$ \\
\hline
\end{tabular}

${ }^{*} p<0.05$. DM Diabetes Mellitus, MI Myocardial infarction, PAD Peripheral arterial disease, $B M I$ Body mass index, $L D L$ Low density lipoprotein, $H D L$ High density lipoprotein

cholesterol levels in the female participants. Rhee et al. (2007) and Okello et al. (2014) observed a female preponderance that was statistically significant [11, 22]. Other studies had similar findings that were not statistically significant $[12,14,23]$. In one study, PAD was more common in males because there was a higher proportion of smokers [9]. Smoking was not common among our subjects- there were no current smokers and previous smoking was insignificant. Other studies we reviewed, found no relationship between sex and the PAD [10, 29].

We observed that older DM patients were less likely to have PAD and there was no relationship between the duration since diagnosis of DM with PAD. Perhaps other risk factors were more common in the younger diabetics such as dyslipidaemia. Mwebaze et al. (2014) and Ogbera et al. (2015) found that PAD was more common in younger DM patients, although this was not significant

Table 3 Adjusted odds ratios for independent correlates of PAD using multiple logistic regression analysis

\begin{tabular}{lll}
\hline Characteristics & Adjusted odds ratio & 95\% Confidence Interval \\
\hline Female sex & 1.57 & $0.85-2.91$ \\
Age $\geq 50$ years & 0.60 & $0.31-1.17$ \\
$\mathrm{BMI} \geq 25 \mathrm{~kg} / \mathrm{m}^{2 *}$ & 2.13 & $1.04-4.36$ \\
Low HDL cholesterol* & 2.31 & $1.04-5.15$
\end{tabular}

${ }^{*} p<0.05$. BMI Body mass index, HDL High density lipoprotein
$[14,15]$. This was different from the observations made in other studies $[9,29]$. Advancing age as well as a longer duration of DM was associated with PAD in some studies in sub-Saharan Africa and elsewhere [10, 13, 23]. It is our theory that in the face of multiple risk factors for PAD including persistent hyperglycaemia and dyslipidaemia, the role of age or a longer duration of DM may be less substantial.

Hyperglycaemia plays a significant role in the pathogenesis of PAD in terms of increasing inflammation, disrupting platelet function and the vascular endothelium as well as altering blood rheology [19]. However, in our study we found no significant relationship between poor glycaemic control as represented by $\mathrm{HbA1c} \geq 7 \%$ and PAD. Rather, the mean HbA1c was greater in the absence of PAD. This was similar to what Ogbera et al. (2015) observed their study [15]. In contrast, there was a significant association between hyperglycaemia and PAD in studies from Asia $[10,11]$. HbA1c is a snapshot of a patient's glycaemic status over a three-month period: it may not be a true reflection of the glycaemic control in that individual over a longer period. At least one other study corroborates this [30].

Dyslipidaemia, in the form of low HDL cholesterol, was an independent correlate of PAD in this study. Few studies corroborate our findings [31]. In two of those studies, elevated total cholesterol and triglycerides were associated with PAD $[9,10]$. Low HDL levels have been associated with atherosclerosis in general. Importantly, 
in contrast to the proportion of patients with dyslipidaemia, few patients were on lipid altering drugs.

Obesity as a risk factor for vascular disease played out in this study: most of the participants with PAD were overweight or obese, according to BMI. This was independent of other factors including dyslipidaemia and poor glycaemic control. This was similar to the findings in studies from Africa and the Middle East [29, 32]. A multi-country study in Asia found a relationship between lower BMI and PAD: few participants in the study were obese or overweight [11]. Truncal obesity, as defined by waist circumference did not correlate with PAD in our research. A likely explanation is that visceral adipose tissue in black Africans may not play a major role in the inflammatory changes seen in PAD [33, 34].

The findings in our study are limited to tertiary hospital settings- it is not applicable to the patients with diabetes in the general population. It is possible that there are other factors associated with PAD in patients with diabetes such as lifestyle choices and economic status, which we did not consider in our research. Exploration of the impact of these factors may prove important in future research on PAD in this population.

\section{Conclusion}

More than a third of our patients with type $2 \mathrm{DM}$ had PAD and this was associated with a younger age group $(<50$ years), female sex, BMI and low HDL cholesterol levels. A BMI of $\geq 25 \mathrm{kgm}^{2}$ and low HDL cholesterol were independent correlates of PAD. Further investigation of the patients with $\mathrm{ABI}$ of $>1.3$ may increase the prevalence. Screening for PAD in patients with DM will prove valuable in our practice. Maintaining a normal BMI and low HDL cholesterol for patients with DM may be key to reducing the occurrence of PAD.

\section{Abbreviations}

ABI: Ankle brachial pressure index; BMI: Body mass index; DM: Diabetes mellitus; HbA1c: Glycosylated haemoglobin; HDL: High density lipoprotein; LDL: Low density lipoprotein; OR: Odds ratio; PAD: Peripheral arterial disease

\section{Acknowledgements}

We wish to acknowledge the efforts of our friends and colleagues who helped us acquire the hand-held Doppler machine for our study.

\section{Authors' contributions}

OA, FA and FP conceptualised the study. OA and FP recruited participants and collected the data. OA and FA analysed and interpreted the patient data. All authors contributed to the writing of the manuscript. All authors read and approved the final manuscript.

\section{Funding}

This study was funded solely by the authors.

\section{Availability of data and materials}

The datasets generated and analysed during the current study are not publicly available because they are still in use but are available from the corresponding author on reasonable request.

\section{Ethics approval and consent to participate}

We obtained ethical approval from the Jos University Teaching Hospital's Health Research Ethical Committee (JUTH/DCS/ADM/127/XIX/5955). All participants were only recruited after giving an informed consent and appending their signature (or thumbprint for the non-literate participants) to the consent form, as approved by the Research Ethical Committee.

\section{Consent for publication}

Not applicable.

\section{Competing interests}

The authors declare that they have no competing interests.

Received: 19 June 2019 Accepted: 21 February 2020

Published online: 28 February 2020

\section{References}

1. Ikem R, Ikem I, Adebayo O, Soyoye D. An assessment of peripheral vascular disease in patients with diabetic foot ulcer. Foot. 2010;20(4):114-7.

2. American Diabetes Association. Peripheral arterial disease in people with diabetes. Diabetes Care. 2003;26(12):3333.

3. Norman PE, Davis WA, Bruce DG, Davis TM. Peripheral arterial disease and risk of cardiac death in type 2 diabetes: the Fremantle diabetes study. Diabetes Care. 2006;29(3):575-80.

4. Weitz Jl, Byrne J, Clagett GP, Farkouh ME, Porter JM, Sackett DL, et al. Diagnosis and treatment of chronic arterial insufficiency of the lower extremities: a critical review. Circulation. 1996;94(11):3026-49.

5. Elhadd TA, Robb R, Jung RT, Stonebridge PA, Belch JJF. Pilot study of prevalence of asymptomatic peripheral arterial occlusive disease in patients with diabetes attending a hospital clinic. Practical Diabetes Int. 1999;16:163-6.

6. Kengne AP, Amoah AG, Mbanya J-C. Cardiovascular complications of diabetes mellitus in sub-Saharan Africa. Circulation. 2005;112(23):3592-601.

7. Hirsch AT, Criqui MH, Treat-Jacobson D, Regensteiner JG, Creager MA, Olin JW, et al. Peripheral arterial disease detection, awareness, and treatment in primary care. JAMA. 2001;286:1317-24.

8. Charles M, Ejskjaer N, Witte DR, Borch-Johnsen K, Lauritzen T, Sandbaek A. Prevalence of neuropathy and peripheral arterial disease and the impact of treatment in people with screen-detected type 2 diabetes: the ADDITIONDenmark study. Diabetes Care. 2011;34(10):2244-9.

9. $\mathrm{Yu} J \mathrm{H}, \mathrm{H}$ wang JY, Shin MS, Jung $\mathrm{CH}$, Kim EH, Lee SA, et al. The prevalence of peripheral arterial disease in Korean patients with type 2 diabetes mellitus attending a university hospital. Diabetes Metab J. 2011;35(5):543-50.

10. Wang L, Du F, Mao H, Wang HX, Zhao S. Prevalence and related risk factors of peripheral arterial disease in elderly patients with type 2 diabetes in Wuhan, Central China. Chin Med J. 2011;124(24):4264-8 2011;124(24):4264-8.

11. Rhee SY, Guan H, Liu ZM, Cheng SW, Waspadji S, Palmes P, et al. Multicountry study on the prevalence and clinical features of peripheral arterial disease in Asian type 2 diabetes patients at high risk of atherosclerosis. Diabetes Res Clin Pract. 2007;76(1):82-92.

12. Rabia K, Khoo E. Prevalence of peripheral arterial disease in patients with diabetes mellitus in a primary care setting. Med J Malays. 2007;62(2):130-3.

13. Umuerri E, Obasohan A. Lower extremity peripheral artery disease: prevalence and risk factors among adult Nigerians with diabetes mellitus. West Afr J Med. 2012;32(3):200-5.

14. Mwebaze RM, Kibirige D. Peripheral arterial disease among adult diabetic patients attending a large outpatient diabetic clinic at a national referral hospital in Uganda: a descriptive cross sectional study; 2014.

15. Ogbera AO, Adeleye O, Solagberu B, Azenabor A. Screening for peripheral neuropathy and peripheral arterial disease in persons with diabetes mellitus in a Nigerian University teaching hospital. BMC Res Notes. 2015;8(1):533.

16. Bernstein EF, Fronek A. Current status of non-invasive tests in the diagnosis of peripheral arterial disease. Surg Clin North Am. 1982;62:473-87.

17. Aboyans V, Criqui MH, Abraham P, Allison MA, Creager MA, Diehm C, et al. Measurement and interpretation of the ankle-brachial index. A Scientific Statement From the American Heart Association. Circulation. 2012;126(24): 2890-909.

18. Criqui MH. Peripheral arterial disease-epidemiological aspects. Vasc Med. 2001;6(1_suppl):3-7. 
19. Schneider DL, Sobel BE. Diabetes and thrombosis. In: Johnstone MT, Veves A, editors. Diabetes and cardiovascular disease. Totowa: Humana Press; 2001.

20. Veves A, Akbari CM, Primavera J, Donaghue VM, Zacharoulis D, Chrzan JS, et al. Endothelial dysfunction and the expression of endothelial nitric oxide synthetase in diabetic neuropathy, vascular disease,and foot ulceration. Diabetes. 1998;47:457-63.

21. Steinberg HOBA. Vascular function,insulin resistance and fatty acids. Diabetologia. 2002;45:623-34.

22. Okello S, Millard A, Owori R, Asiimwe SB, Siedner MJ, Rwebembera J, et al. Prevalence of lower extremity peripheral artery disease among adult diabetes patients in southwestern Uganda. BMC Cardiovasc Disord. 2014; 14(1):75.

23. Oyelade BO, OlaOlorun AD, Odeigah LO, Amole IO, Adediran OS. The prevalence of peripheral arterial disease in diabetic subjects in south-west Nigeria. Afr J Prim Health Care Fam Med. 2012;4(1):6.

24. World Health Organization Waist circumference and waist-hip ratio: report of a WHO expert consultation. 2008.

25. Dormandy JA, Betteridge DJ, Schernthaner G, Pirags V, Norgren L. Impact of peripheral arterial disease in patients with diabetes--results from PROactive (PROactive 11). Atherosclerosis. 2009;202(1):272-81.

26. National High Blood Pressure Education Program The seventh report of the Joint National Committee on prevention, detection, evaluation, and treatment of high blood pressure. 2004.

27. American Diabetes Association. Standards of medical Care in Diabetes. Diabetes Care. 2013;36(suppl 1):S11-66.

28. Alberti K, Zimmet P, Shaw J. Metabolic syndrome-a new world-wide definition. A consensus statement from the international diabetes federation. Diabet Med. 2006;23(5):469-80.

29. Yeboah K, Puplampu P, Yorke E, Antwi DA, Gyan B, Amoah AG. Body composition and ankle-brachial index in Ghanaians with asymptomatic peripheral arterial disease in a tertiary hospital. BMC Obesity. 2016;3(1):27.

30. Dziemiok P, Szczesniak G, Kostrzewa-Zablocka E, Paprzycki P, KorzonBurakowska A. Is the advancement of diabetic angiopathy evaluated as ankle-brachial index directly associated with current glycaemic control? Ann Agric Environ Med. 2012;19(3):563-6.

31. Chou CK, Weng SW, Chang HW, Chen CY, Su SC, Liu RT. Analysis of traditional and nontraditional risk factors for peripheral arterial disease in elderly type 2 diabetic patients in Taiwan. Diabetes Res Clin Pract. 2008; 81(3):331-7.

32. Akram J, Aamir AU, Basit A, Qureshi MS, Mehmood T, Shahid SK, Khoso IA, Ebrahim MA, Omair A. Prevalence of peripheral arterial disease in type 2 diabetics in Pakistan. JPMA-Journal of the Pakistan Medical Association. 2011;61(7):644

33. Carroll JF, Chiapa AL, Rodriquez M, Phelps DR, Cardarelli KM, Vishwanatha $\mathrm{JK}$, et al. Visceral fat, waist circumference, and BMI: impact of race/ethnicity. Obesity. 2008;16(3):600-7.

34. Després J-P, Lemieux I, Bergeron J, Pibarot P, Mathieu P, Larose E, et al. Abdominal obesity and the metabolic syndrome: contribution to global cardiometabolic risk. Arterioscler Thromb Vasc Biol. 2008;28(6):1039-49.

\section{Publisher's Note}

Springer Nature remains neutral with regard to jurisdictional claims in published maps and institutional affiliations.

\section{Ready to submit your research? Choose BMC and benefit from:}

- fast, convenient online submission

- thorough peer review by experienced researchers in your field

- rapid publication on acceptance

- support for research data, including large and complex data types

- gold Open Access which fosters wider collaboration and increased citations

- maximum visibility for your research: over $100 \mathrm{M}$ website views per year

At BMC, research is always in progress.

Learn more biomedcentral.com/submissions 